\title{
Impact of Asymmetry of Over-Head Power Line Parameters on Short-Circuit Currents
}

\author{
Žaneta Eleschová ${ }^{1)}$ and Marián Ivanič ${ }^{2)}$ \\ 1) 2) Slovak University of Technology in Bratislava, Faculty of Electrical Engineering and Information Technology, \\ Institute of Power and Applied Electrical Engineering, Bratislava, Slovakia, \\ e-mail: ${ }^{1)}$ zaneta.eleschova@stuba.sk, ${ }^{2)}$ marian.ivanic@stuba.sk
}

\begin{abstract}
This paper analyses the impact of asymmetry of over-head power line parameters on short circuit currents when three-phase fault and phase-to-ground fault occur. The calculation results with consideration of an asymmetry of the power line parameters are confronted with the calculation in accordance with the Slovak standard STN EN 60909 which does not consider asymmetry of equipment parameters in the power system. The calculation of short-circuit conditions was carried out for two types of $400 \mathrm{kV}$ power line towers on which is a considerably different arrangement of phase conductors.
\end{abstract}

Keywords - over-head lines, power line parameters, asymmetry, short-circuit current.

\section{INTRODUCTION}

Short-circuit currents are addressed according to the Slovak standard STN EN 60909. The calculation according to this standard does not consider asymmetry of power system parameters and uses the method of symmetrical components instead. The objective of this paper is to compare the calculation considering asymmetry of the power system parameters with the calculation in accordance with the standard.

Over-head power lines represent a dominant part of the power system and if the phases are not transposed on towers, one of the equipment in the power system contains a considerable asymmetry of electrical parameters. Therefore, the calculation of short-circuit conditions was carried out on a simplified model: an ideal source and power line. The power line was modelled for two types of $400 \mathrm{kV}$ power line towers with a considerable arrangement of phase conductors.

The following values of the short-circuit current have been evaluated from the simulation results:

- RMS value which represents the initial shortcircuit current $\mathrm{I}_{\mathrm{k}}^{\prime \prime}$,

- peak value with consideration of the DC component maximum value which represents peak short-circuit current $i_{p}$.

\section{RESULTS OF SHORT-CIRCUIT SIMULATIONS WITH CONSIDERATION OF ASYMMETRY OF POWER LINE PARAMETERS}

The calculation of the power line parameters as well as short-circuit simulations were carried out in EMTP (Electro-Magnetic Transient Program). A simplified model for calculation of the short-circuit currents is depicted in Fig. 1.

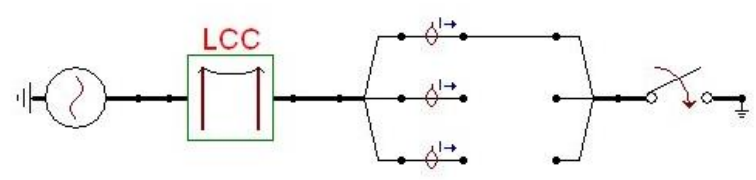

Fig.1. Simplified model in EMTP.

\section{A. Input Parameters}

The power line was modelled with the following two types of towers:

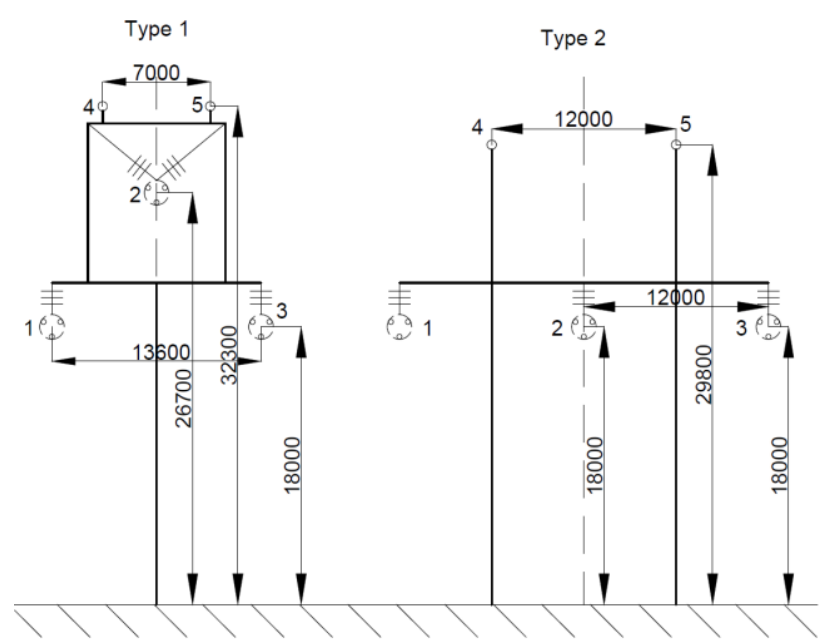

Fig. 2. Types of towers.

The first type of tower represents a deployment of conductors equally distant but in a different height above the ground. The conductors of the second type of tower have the same height but marginal conductors are placed in a double distance.

The following table illustrates the conductor parameters:

TABLE I.

PARAMETERS OF CONDUCTORS

\begin{tabular}{|c|c|c|}
\hline ACSR conductor & $\begin{array}{c}\text { Ground conductor } \\
120 \text { AlFe6 }\end{array}$ & $\begin{array}{c}\text { Phase conductor } \\
\text { 450 AlFe6 }\end{array}$ \\
\hline $\mathrm{R}_{\mathrm{DC}}[\Omega / \mathrm{km}]$ & 0,225 & 0,065 \\
\hline$\xi[-]$ & 0,809 & 0,818 \\
\hline $\mathrm{d}_{\mathrm{l}}[\mathrm{mm}]$ & 16 & 29,76 \\
\hline
\end{tabular}

Soil resistivity was $100 \Omega / \mathrm{m}$. 
Parameters of the asymmetrical (untransposed) power line are provided in Table II and parameters of the transposed power line in Table III which indicates values in symmetrical component systems while the length of the power line is $60 \mathrm{~km}$.

TABLE II.

PARAMETERS OF UNTRANSPOSED LINES

\begin{tabular}{|c|c|c|c|c|c|c|c|}
\hline \multicolumn{2}{|c|}{ Tower } & \multicolumn{3}{c|}{ Type 1 } & \multicolumn{3}{c|}{ Type 2 } \\
\hline \multicolumn{2}{|c|}{ Phase } & L1 & L2 & L3 & L1 & L2 & L3 \\
\hline \multirow{4}{*}{$\begin{array}{c}\mathrm{R} \\
{[\Omega]}\end{array}$} & L1 & 3,65 & 2,51 & 2,35 & 3,70 & 2,43 & 2,35 \\
\cline { 2 - 8 } & L2 & 2,51 & 4,08 & 2,51 & 2,43 & 3,79 & 2,43 \\
\cline { 2 - 8 } & L3 & 2,35 & 2,51 & 3,65 & 2,35 & 2,43 & 3,70 \\
\hline \multirow{4}{*}{$\left.\begin{array}{c}\mathrm{X} \\
{[\Omega}\end{array}\right]$} & L1 & 26,29 & 7,84 & 8,62 & 26,21 & 8,60 & 6,47 \\
\cline { 2 - 8 } & L2 & 7,84 & 22,85 & 7,84 & 8,60 & 25,35 & 8,60 \\
\cline { 2 - 8 } & L3 & 8,62 & 7,84 & 26,29 & 6,47 & 8,60 & 26,21 \\
\hline \multirow{4}{*}{$\begin{array}{c}k \\
{[n F]}\end{array}$} & L1 & 683,74 & $-97,22$ & $-61,25$ & 672,61 & $-84,04$ & $-19,34$ \\
\cline { 2 - 8 } & L2 & $-97,22$ & 695,02 & $-97,22$ & $-84,04$ & 690,60 & $-84,04$ \\
\cline { 2 - 8 } & L3 & $-61,25$ & $-97,22$ & 683,74 & $-19,34$ & $-84,04$ & 672,62 \\
\hline
\end{tabular}

TABLE III.

PARAMETERS OF TRANSPOSED LINES IN SYMMETRICAL COMPONENTS

\begin{tabular}{|c|c|c|}
\hline Tower & Type 1 & Type 2 \\
\hline $\mathrm{R}_{0}[\Omega]$ & 8,76 & 8,60 \\
\hline $\mathrm{R}_{1}[\Omega]$ & 1,36 & 1,34 \\
\hline $\mathrm{X}_{0}[\Omega]$ & 41,40 & 41,77 \\
\hline $\mathrm{X}_{1}[\Omega]$ & 17,05 & 18,03 \\
\hline $\mathrm{C}_{0}[\mathrm{nF}]$ & 518,25 & 555,05 \\
\hline $\mathrm{C}_{1}[\mathrm{nF}]$ & 773,70 & 742,06 \\
\hline
\end{tabular}

\section{B. Results of Short-Circuit Simulations}

As mentioned above, the model in EMTP consisted of an ideal power source and power line. The source voltage was established in accordance with the Slovak standard STN EN 60909 as follows: $c U_{n} / \sqrt{3}$, where $\mathrm{c}=1,05$ and $\mathrm{U}_{\mathrm{n}}=400 \mathrm{kV}$.

It was made a simulation of the three-phase fault and phase-to-ground fault at the end of the power line while the RMS value and peak value were evaluated.

\section{Results for Three-Phase Fault}

The three-phase fault is a symmetrical type of fault. The short-circuit current is the same in all three phases when asymmetry of power system parameters was not considered. Following the simulations results, it is evident that the short-circuit currents are different in case of this symmetrical fault when the asymmetry of the power line parameters was considered, the short-circuit currents are different also in case of this symmetrical fault. The shortcircuit current RMS values are included in Table IV.

For the transposed (symmetrical) power line, the RMS value is $14,2 \mathrm{kA}$ for the first type of tower and $13,4 \mathrm{kA}$ for the second type of tower. Table IV includes also values of relative deviations from RMS values of the short-circuit currents in individual phases while untransposed power line was considered, calculated according to the following relation:

$$
\delta=\frac{I_{\mathrm{UL}}-I_{\mathrm{TL}}}{I_{\mathrm{TL}}} 100
$$

$\mathrm{UL}$ - untransposed line

$\mathrm{TL}$ - transposed line

TABLE IV

RMS VALUES OF SHORT-CIRCUIT CURRENTS

\begin{tabular}{|c|c|c|c|}
\hline \multicolumn{2}{|c|}{ Tower type } & Type 1 & Type 2 \\
\hline \multirow{4}{*}{ I [kA] } & TL & 14,2 & 13,4 \\
\cline { 2 - 4 } & L1 & 13,8 & 12,9 \\
\cline { 2 - 4 } & L2 & 14,8 & 14,8 \\
\cline { 2 - 4 } & L3 & 14,1 & 13,0 \\
\hline \multirow{3}{*}{$\delta[\%]$} & L1 & $-2,6$ & $-4,0$ \\
\cline { 2 - 4 } & L2 & 4,3 & 10,4 \\
\cline { 2 - 4 } & L3 & $-0,4$ & $-2,9$ \\
\hline
\end{tabular}

The biggest difference in RMS values of the shortcircuit current $(10,4 \%)$ is in the middle phase for tower of the second type, as can be seen from the results.

The peak values of the short-circuit currents were also evaluated while the development of the maximum DC component value was considered. The DC component is dependent on the moment of the short-circuit occurrence.

The time behaviour of the short-circuit currents with the maximum DC component are shown in the following figures.

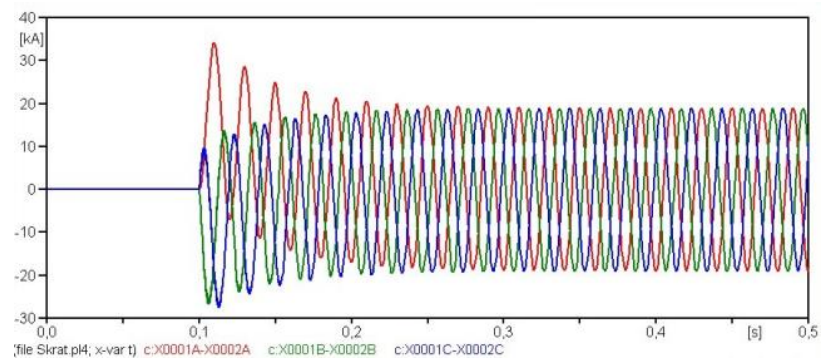

Fig. 3. The time behaviour of short-circuit current upon three-phase fault.

The amplitudes of the short-circuit currents are shown in the table below.

TABLE V.

PEAK VALUES OF SHORT-CIRCUIT CURRENTS WITH CONSIDERATION OF MAXIMUM DC COMPONENT

\begin{tabular}{|c|c|c|c|}
\hline \multicolumn{2}{|c|}{ Tower type } & Type 1 & Type 2 \\
\hline \multirow{4}{*}{$\mathrm{I}_{\max }[\mathrm{kA}]$} & TL & 35,9 & 34,2 \\
\cline { 2 - 4 } & L1 & 34,9 & 32,8 \\
\cline { 2 - 4 } & L2 & 36,4 & 37,3 \\
\cline { 2 - 4 } & L3 & 35,9 & 33,4 \\
\hline \multirow{4}{*}{$\delta[\%]$} & L1 & $-2,9$ & $-4,1$ \\
\cline { 2 - 4 } & L2 & 1,3 & 9,0 \\
\cline { 2 - 4 } & L3 & $-0,1$ & $-2,4$ \\
\hline
\end{tabular}


There are differences even in peak values of the shortcircuit currents, in percentage terms they are a bit different than in case of the RMS values.

The difference is caused by different time constants of the DC components in individual phases, i.e. different decay. It means that the asymmetry of the power line parameters has the impact not only on the AC component value of the short-circuit current but also on time constant of the DC component of the short-circuit current.

\section{Results for Phase-to-Ground Fault}

The short-circuit current for the transposed line in case of the phase-to-ground fault is the same for every single phase. For the untransposed line, simulations of the phaseto-ground fault were carried out for each phase separately.

TABLE VI.

RMS VALUES OF SHORT-CIRCUIT CURRENTS

\begin{tabular}{|c|c|c|c|}
\hline \multicolumn{2}{|c|}{ Tower type } & Type 1 & Type 2 \\
\hline \multirow{4}{*}{ I [kA] } & TL & 9,5 & 9,3 \\
\cline { 2 - 4 } & L1 & 9,2 & 9,2 \\
\cline { 2 - 4 } & L2 & 10,4 & 9,5 \\
\cline { 2 - 4 } & L3 & 9,2 & 9,2 \\
\hline \multirow{4}{*}{$\delta[\%]$} & L1 & $-3,9$ & $-1,0$ \\
\cline { 2 - 4 } & L2 & 8,8 & 2,1 \\
\cline { 2 - 4 } & L3 & $-3,9$ & $-1,0$ \\
\hline
\end{tabular}

The highest difference is in the middle phase for the tower of the first type which has the biggest height above the ground but is the closest to the ground conductor. The results of the short-circuit currents for the phase-to-ground fault are almost identical for the tower of the second type.

Similar results are valid also for the peak values of the short-circuit currents and again (as for three-phase fault), the percentage differences of the peak values are not the same as for the RMS values.

TABLE VII

Peak VAlues of SHORT-CirCuit CuRRENTS With CONSIDERATION OF MAXIMUM DC COMPONENT

\begin{tabular}{|c|c|c|c|}
\hline \multicolumn{2}{|c|}{ Tower type } & Type 1 & Type 2 \\
\hline \multirow{4}{*}{$\mathrm{I}_{\max }[\mathrm{kA}]$} & $\mathrm{TL}$ & 22,1 & 21,7 \\
\cline { 2 - 4 } & L1 & 21,3 & 21,4 \\
\cline { 2 - 4 } & L2 & 24,4 & 21,9 \\
\cline { 2 - 4 } & L3 & 21,3 & 21,4 \\
\hline \multirow{3}{*}{$\delta[\%]$} & L1 & $-3,8$ & $-1,2$ \\
\cline { 2 - 4 } & L2 & 10,2 & 1,1 \\
\cline { 2 - 4 } & L3 & $-3,8$ & $-1,2$ \\
\hline
\end{tabular}

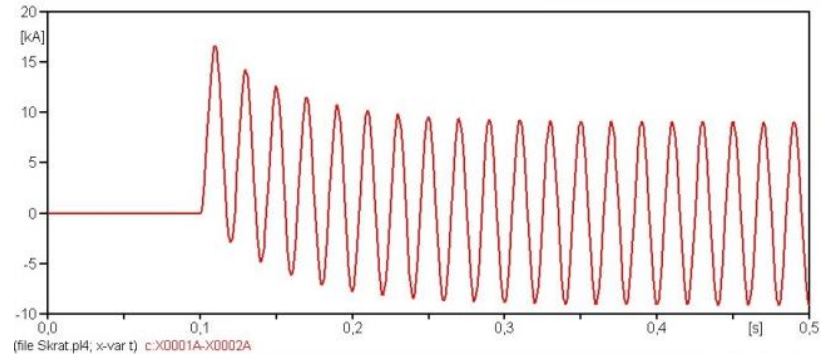

Fig. 4. The time behaviour of short-circuit current upon phase-to-ground fault.

\section{CALCULATION ACCORDING TO THE SLOVAK STANDARD STN EN 60909}

The transposed line parameters of EMTP, i.e. from Table III were considered for calculation of the shortcircuit impedance.

The initial short-circuit currents and peak short-circuit currents for the three-phase fault and phase-to-ground fault were calculated. The calculation according to the Slovak standard STN EN 60909 is based on the method of symmetrical component systems.

The initial short-circuit current is given by:

- Three-phase fault:

$$
I_{k 3}^{\prime \prime \prime}=\frac{c U_{n}}{\sqrt{3}\left|\bar{Z}_{1}\right|}
$$

- Phase-to-ground fault:

$$
I_{k 1}^{\prime \prime \prime}=\frac{c \sqrt{3} U_{n}}{\left|\bar{Z}_{1}+\bar{Z}_{2}+\bar{Z}_{0}\right|}=\frac{c \sqrt{3} U_{n}}{\left|2 \bar{Z}_{1}+\bar{Z}_{0}\right|}
$$

$\bar{Z}_{1}$ - positive sequence short-circuit impedance

$\bar{Z}_{2}$ - negative sequence short-circuit impedance

$\overline{\mathrm{Z}}_{0}$ - zero sequence short-circuit impedance

The value of the peak short-circuit current is determined according to the following relation:

$$
\begin{gathered}
i_{p}=\sqrt{2} I_{k}^{\prime \prime \prime} K \\
K=1,02+0,98 e^{\frac{-3 R_{k}}{X_{k}}}
\end{gathered}
$$

\section{A. Calculation for Tower Type 1}

TABLE VIII

SHORT-CIRCUIT IMPEDANCES

\begin{tabular}{|l|c|}
\hline positive sequence & $17,103 \Omega \angle 85,46^{\circ}$ \\
\hline zero sequence & $42,317 \Omega \angle 78,0$ \\
\hline
\end{tabular}
SHORT-CIRCUIT CURRENTS FOR THREE PHA
\begin{tabular}{|c|c|}
\hline $\mathrm{I}_{\mathrm{k} 3}^{\prime \prime \prime}$ & $14,18 \mathrm{kA}$ \\
\hline $\mathrm{K}$ & 1,792 \\
\hline $\mathrm{i}_{\mathrm{p}}$ & $35,93 \mathrm{kA}$ \\
\hline
\end{tabular}


TABLE X.

SHORT-CIRCUIT CURRENTS FOR PHASE TO GROUND FAULT

\begin{tabular}{|c|c|}
\hline $\mathrm{I}_{\mathrm{k} 1}^{\prime \prime \prime}$ & $9,526 \mathrm{kA}$ \\
\hline $\mathrm{K}$ & 1,641 \\
\hline $\mathrm{i}_{\mathrm{p}}$ & $22,11 \mathrm{kA}$ \\
\hline
\end{tabular}

\section{B. Calculation for Tower Type 2}

TABLE XI.

SHORT-CIRCUIT IMPEDANCES

\begin{tabular}{|l|l|}
\hline positive sequence & $18,08 \Omega \angle 85,74^{\circ}$ \\
\hline zero sequence & $42,65 \Omega \angle 78,37^{\circ}$ \\
\hline
\end{tabular}

TABLE XII

SHORT-CIRCUIt CURRENTS FOR Three Phase FAult

\begin{tabular}{|c|c|}
\hline $\mathrm{I}_{\mathrm{k} 3}^{\prime \prime \prime}$ & $13,41 \mathrm{kA}$ \\
\hline $\mathrm{K}$ & 1,804 \\
\hline $\mathrm{i}_{\mathrm{p}}$ & $34,21 \mathrm{kA}$ \\
\hline
\end{tabular}

TABLE XIII

ShorT-CirCUIT CuRRENTS FOR PHASE TO GROUND FAULT

\begin{tabular}{|c|c|}
\hline $\mathrm{I}_{\mathrm{k} 1}^{\prime \prime \prime}$ & $9,25 \mathrm{kA}$ \\
\hline $\mathrm{K}$ & 1,654 \\
\hline $\mathrm{i}_{\mathrm{p}}$ & $21,64 \mathrm{kA}$ \\
\hline
\end{tabular}

The above mentioned results prove that the results of the short-circuit currents are the same as the results of simulations for the transposed power line which verifies the results of the simulation.

\section{CONCLUSION}

This paper deals with the impact of an asymmetry of over-head power line parameters on the short circuit currents in its individual phases. The objective of the paper is to compare calculation of currents with consideration of asymmetry of the power line parameters, with calculation in accordance with the valid standard STN EN 60909 on which the asymmetry of parameters is neglected. The important result is that the short-circuit currents in some of the phases are higher than the shortcircuit current calculated in accordance with the standard considering untransposed power line.

Taking into consideration the three-phase fault, for the second type of tower the difference was up to $10,4 \%$ for the middle phase. The positive sequence impedance applies only with three-phase fault, therefore compared to the transposed line the biggest difference of the shortcircuit current is in the middle phase which has the shortest distance against other two phases. The distances of the phase conductors on the first type of tower are approximately the same and the currents in phases within the three-phase fault are approximately the same as well. The calculation of the phase-to-ground fault proved that the biggest difference $(8,8 \%)$ was for the first type of tower, again in the middle phase. Also the zero sequence is included into calculation for the phase-to-ground fault which depends on the distance of the phase conductors from the ground conductor. The phase conductors on the second type of tower have approximately the same distance from the ground conductor and the short-circuit currents in individual phases for the phase-to-ground fault are approximately the same. The arrangement of conductors on the first type of tower is different, the middle phase is the closest to the ground conductor and the short-circuit current for phase-to-ground fault is the highest in this phase.

The other important observation from the results is that the asymmetry of parameters influences time constant of the DC component and so influences other short-circuit quantities such as: peak short-circuit current, thermal short-circuit current, unsymmetrical breaking current. Thus, these quantities are influenced by various values of the initial short-circuit current in individual phases on one hand and by various time constants of the DC component for individual phases on the other hand.

This implies that correction factors taking into account asymmetry of parameters should be defined when calculating short-circuit currents.

\section{ACKNOWLEDGMENT}

These publications are the result of implementation of the project: "Increase of Power Safety of the Slovak Republic" (ITMS: 26220220077) supported by the Research \& Development Operational Programme funded by the ERDF.
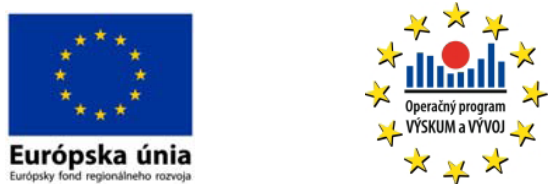

\section{REFERENCES}

[1] D. Reváková, Ž. Eleschová, and A. Beláň, Prechodné javy v elektrizačných sústavách. Bratislava: Slovenská technická univerzita v Bratislave, 2008.

[2] M. Ivanič and Ž. Eleschová, "The faults with consideration of line asymetry parameters," in Power engineering 2016: Control of Power Systems 2016: 12th International scientific conference. Tatranské Matliare, Slovakia. May 31 - June 2, 2016. 1. vyd. Bratislava: Slovak University of Technology, 2016, s. 73-77. ISBN 978-80-89402-84-7.

[3] STN EN 60909-1, "Výpočet skratových prúdov v trojfázových striedavých sústavách."

[4] Š. Fecko, D. Reváková., L. Varga, J. Lago, and S. Ilenin, Vonkajšie elektrické vedenia. Bratislava: STU FEI, 2010.

[5] A. J. Schwab, Elektroenergiesysteme. Erzeugung, Transport, Übertragung und Verteilung elektrischer Energie. Berlin Heidelberg, Springer, 2012. 